\title{
A QUICK REVIEW OF 2D TOPOGRAPHIC TRAVELTIMES
}

\author{
German Garabito ${ }^{1}$, Pedro A. Chira-Oliva² ${ }^{2}$ Martin Tygel ${ }^{3}$ and Lúcio T. Santos ${ }^{4}$ \\ Recebido em 6 janeiro, 2005 / Aceito em 10 marco, 2005 \\ Received on January 6, 2005 / Accepted on March 10, 2005
}

\begin{abstract}
The Common-Reflection-Surface (CRS) stacking method was originally introduced as a data-driven method to simulate zero-offset sections from 2-D reflection pre-stack data acquired along a straight line. This approach is based on a second-order hiperbolic traveltime approximation parameterized with three kinematic wavefield attributes. In land data, topographic effects play an important role in seismic data processing and imaging. Thus, this feature has been recently considered by the CRS method. In this work we review the CRS traveltime approximations that consider the smooth and rugged topography. In addition, we also review the Multifocusing traveltime for a rugged topography. By means of a simple synthetic example, we finally provide first comparisons between the various traveltime expressions.
\end{abstract}

Keywords: Traveltime, CRS, Multifocus, Topography.

RESUMO. 0 método de empilhamento Superfície de Reflexão Comum (SRC) foi originalmente introduzido como um método data-driven para simular seções afastamento-nulo a partir de dados sísmicos de reflexão pré-empilhados 2-D adquiridos ao longo de uma linha de aquisição reta. Este método está baseado em uma aproximação de tempos de trânsito hiperbólica de segunda ordem parametrizada com três atributos cinemáticos do campo de onda. Em dados terrestres, os efeitos topográficos desempenham um papel importante no processamento e imageamento de dados sísmicos. Assim, esta característica tem sido considerada recentemente pelo método SRC. Neste trabalho apresentamos uma revisão das aproximações de tempos de trânsito SRC que consideram topografia suave e rugosa. Adicionalmente, nós revemos também a aproximação de tempos de trânsito Multifoco para o caso da topografia rugosa. Por meio de um exemplo sintético simples, nós fornecemos finalmente as primeiras comparações entre as diferentes expressões de tempos de trânsito.

Palavras-chave: Tempos de trânsito SRC, Multifoco, Topografia.

\footnotetext{
1 Universidade Federal do Pará, Departamento de Geofísica, Rua Augusto Corrêia, 01, Campus Universitário do Guamá, Caixa Postal 1611 - CEP: 66.017-970; Tel.: (91)211-1473 / Fax: (91)211-1671 - E-mail: german@ufpa.br

2 Universidade Federal do Pará, Departamento de Geofísica, Rua Augusto Corrêia 1, Campus Universitário do Guamá, Caixa Postal 1611 - CEP 66017-970; Tel: (091) 3183-1473; Fax: (091) 3183-1671 - E-mail: chira@ufpa.br

3 UNICAMP - IMECC, Praça Sergio Buarque de Holanda, 651, Cidade Universitária, Barão Geraldo, Caixa Postal 6065 - 13083-859 Campinas, São Paulo, Brasil -E-mail: tyge|@unicamp.br

4 Departamento de Matemática Aplicada, IMECC - UNICAMP, Caixa Postal 6065, 13081-970 Campinas, SP, Brasil - Tel: (19) 3788-5975; Fax: (19) 3289-5766 -E-mail: lucio@ime.unicamp.br
} 


\section{INTRODUCTION}

The Common-Reflection-Surface (CRS) and the Multifocus (MF) methods are designed to produce clear stacked sections and useful time-domain attributes by means of coherence analysis methods directly applied to multicoverage reflection data. In this way, both methods, that have a similar purpose and approach as the well-established common-midpoint (CMP) method, represent powerful extensions of the latter. As opposed to the CMP method that is applied to CMP gathers and extracts a single parameter (the normal-moveout (NMO) velocity) on manually picked events, the CRS and MF methods (a) make full use of the available multicoverage data by applying the stacking procedure on supergathers that are free from the CMP restriction; (b) extract more parameters (three in the 2D situation) at each time sample of the stacked section to be constructed and (c) the procedure is applied to all time samples without the need of event selection. The CRS and MF methods fall into the category of the so-called macro-model independent or data-driven time-domain methods (see, e.g., Hubral (1999) for a general account and discussion).

A distinctive feature of the CRS and MF methods is the use of specific multiparameter traveltime moveouts. The parameters of these moveout expressions are directly inverted from the data by means of coherence analysis (semblance) procedures. With the help of the inverted parameters, the obtained moveouts are employed to stack the data. Note that this is exactly what the conventional velocity analysis method does under the restriction of the one-parameter NMO traveltimes applied to CMP gathers.

Originally, both the CRS and the MF have been derived under the following assumptions: (a) 2D propagation; (b) locallyconstant and supposedly known near-surface velocity and (c) no topographic effects along the seismic line. The latter condition means that the data have been acquired on a horizontal seismic line or preprocessed for statics and residual statics to a horizontal datum before the application of the CRS or MF method.

Under these considerations, the CRS and MF moveouts are expressed as functions of three parameters, namely the emergence angle, $\beta_{0}$, of the zero-offset (Z0) ray with respect to the (planar) surface normal, and two wavefront curvatures, $K_{N I P}$ and $K_{N}$, of the so-called NIP- and N-waves that relate to the ZO ray at its emergence point. We recall that the abbreviation NIP stands for normal-incident-point, namely the point where the ZO ray hits the reflector and that the NIP-wave is a fictitious wave that starts as a point source at NIP and progresses upwards to the measurement surface with half the medium velocity. In the same way, the abbreviation $\mathrm{N}$-wave, stands for the normal wave, which is also a fictitious wave that starts as a wavefront with the shape of the reflector at NIP and progresses upwards with half of the medium velocity. For detailed description and discussion of the NIP- and $\mathrm{N}$-waves, the reader is referred to Hubral (1983).

It is to be observed that the CRS and MF methods can also be normally applied in the case the above requirements are not met. In that case, the three-parameter CRS and MF represent simply stacking parameters that provide a best fit to the reflection events, but cannot be directly attached to the above-mentioned seismic propagation attributes (angles and curvatures). For example, the classical CRS and MF expressions consider the condition of a locally constant near-surface velocity. This means that that the near-surface velocity is considered constant in the vicinity of each central point but can vary as we change from each central point to another. To be consistent with the second-order formulation, the traveltime expression has to consider, not only the velocity, but also its gradient at each central point. As a consequence, wrong near-surface velocities will give rise to wrong emerging angles, even though correct ray parameters can be extracted. In the same way, topographic effects, if not correctly taken into account, will contaminate the CRS attributes affecting their interpretation.

For a planar or smoothly curved measurement surface, the 2D CRS (hyperbolic) traveltime that takes full consideration of the velocity gradient at the central point is presented in Chira et al. (2001). In the MF traveltime expressions, velocity gradients at the central points are not considered. To our knowledge, examples of the influence of the velocity gradients have not yet been provided in the literature.

In this paper, the usual assumption of a locally-constant nearsurface velocity will be also adopted, our attention being concentrated on the incorporation of topography into the traveltime expressions.

\section{D CRS AND MF TRAVELTIMES FOR A PLANAR MEASUREMENT SURFACE}

We recall the "classical" 2D CRS and MF moveout expressions in the simple case of a planar measurement surface. More explicitly, we suppose that all source and receiver pairs are located on a horizontal seismic line. On the seismic line, we assume a fixed point, called central point, on which a simulated Z0 trace is to be constructed by stacking along traces that belong to (generally non-symmetric) nearby source-receiver. As explained above, we also consider a constant velocity in the vicinity of the central point. We adopt midpoint and half-offset coordinates $\left(x_{m}, h\right)$ for the location of a source-receiver in the vicinity of the central point 
$X_{0}=\left(x_{0}, 0\right)$. We denote $m=x_{m}-x_{0}$, by $T_{0}$ the (two-way) reflection time along the $Z 0$ (central) ray and by $v_{0}$ the velocity at the central point. As explained above, we assume that the velocity remains constant for all source-receiver locations where the traveltime is to be computed. Finally, $\beta_{0}, K_{N I P}$ and $K_{N}$ denote the emergence angle and the curvatures of the NIP and N waves that refer to the $Z 0$ ray as observed at $X_{0}$. Under these considerations, the CRS traveltime reads (see, e.g., Jäger et al. (2001))

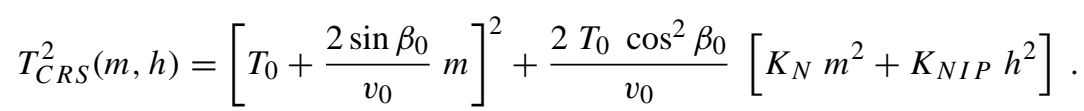

For the same situation of a planar measurement surface, the corresponding 2D MF traveltime is given by (see, e.g., Gelchinsky et al. (1999) with a different notation)

$$
\begin{aligned}
T_{M F}(m, h)=T_{0} & +\frac{1}{v_{0} K_{S}}\left[\sqrt{\left[K_{S}(m-h)+\sin \beta_{0}\right]^{2}+\cos ^{2} \beta_{0}}-1\right] \\
& +\frac{1}{v_{0} K_{G}}\left[\sqrt{\left[K_{G}(m+h)+\sin \beta_{0}\right]^{2}+\cos ^{2} \beta_{0}}-1\right],
\end{aligned}
$$

where

$$
K_{S}=\frac{K_{N}-\sigma K_{N I P}}{1-\sigma}, \quad K_{G}=\frac{K_{N}+\sigma K_{N I P}}{1+\sigma}
$$

and

$$
\sigma=\frac{h}{m+\left(m^{2}-h^{2}\right) K_{N I P} \sin \beta_{0}} .
$$

\section{CRS APPROXIMATION FOR SMOOTH TOPOGRAPHY}

The CRS traveltime expression (1) admits a natural extension to the case of a smoothly curved measurement surface. More specifically, let us assume that, at the central point and with respect to a horizontal datum, the seismic line has curvature, $K_{0}$ and dip $\alpha_{0}$. See Figure 1(a). Moreover, let $\gamma_{0}$ denote the emergence angle of the $Z 0$ central ray with respect to the normal to the curved seismic line at the central point. As shown in Chira (2003) (with a different notation), the CRS traveltime for a source-receiver pair located by $(m, h)$ is given by

$$
\begin{aligned}
& T_{C R S}^{2}(m, h)=\left[T_{0}+\frac{2 \sin \gamma_{0}}{v_{0} \cos \alpha_{0}} m\right]^{2} \\
& +\frac{2 T_{0} \cos \gamma_{0}}{v_{0} \cos ^{2} \alpha_{0}}\left[K_{N} \cos \gamma_{0}-K_{0}\right] m^{2} \\
& \quad+\frac{2 T_{0} \cos \gamma_{0}}{v_{0} \cos ^{2} \alpha_{0}}\left[K_{N I P} \cos \gamma_{0}-K_{0}\right] h^{2} .
\end{aligned}
$$

We ready verify that, in the case of a horizontal seismic line, we have $K_{0}=\alpha_{0}=0$ and $\gamma_{0}=\beta_{0}$, so that equation (5) reduces to its previous counterpart equation (1), as expected.

As reported in Chira (2003), the traveltime moveout (5) were tested for a synthetic model of smooth topography with good results. The formulation breaks down, however, as the topography becomes more pronounced.

\section{CRS AND MF APPROXIMATIONS FOR RUGGED TOPO- GRAPHY}

We now consider the extension of the CRS traveltime to the case of arbitrary (rugged) topography. Following Zhang et al. (2002), we find useful to consider vector midpoint, $\mathbf{m}$, and half-offset, $\mathbf{h}$, coordinates with respect to the Cartesian system of horizontal datum and downward vertical. See Figure 1(b). More specifically, we set $\mathbf{m}=\left(m_{x}, m_{z}\right)$ and $\mathbf{h}=\left(h_{x}, h_{z}\right)$ which locate the corresponding source and receiver pair as $S=\mathbf{m}-\mathbf{h}$ and $G=\mathbf{m}+\mathbf{h}$, respectively. As shown in Zhang et al. (2002), we have

$$
\begin{gathered}
T_{C R S}^{2}(\mathbf{m}, \mathbf{h})=\left[T_{0}-\frac{2}{v_{0}}\left(m_{x} \sin \beta_{0}+m_{z} \cos \beta_{0}\right)\right]^{2} \\
+\frac{2 T_{0} K_{N}}{v_{0}}\left(m_{x} \cos \beta_{0}-m_{z} \sin \beta_{0}\right)^{2} \\
+\frac{2 T_{0} K_{N I P}}{v_{0}}\left(h_{x} \cos \beta_{0}-h_{z} \sin \beta_{0}\right)^{2} .
\end{gathered}
$$

The corresponding MF traveltime for rugged topography has been described in Gurevich et al. (2002). In our notation, the $\mathrm{MF}$ is given by 


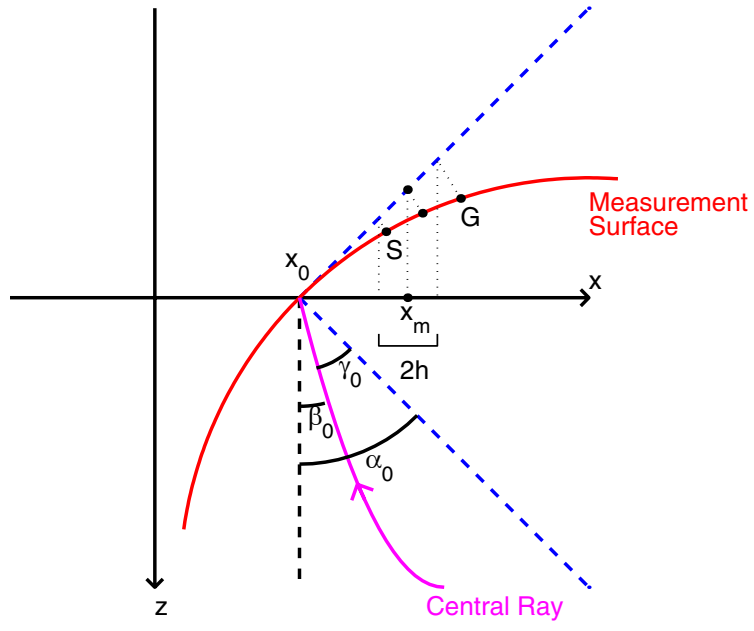

(a)

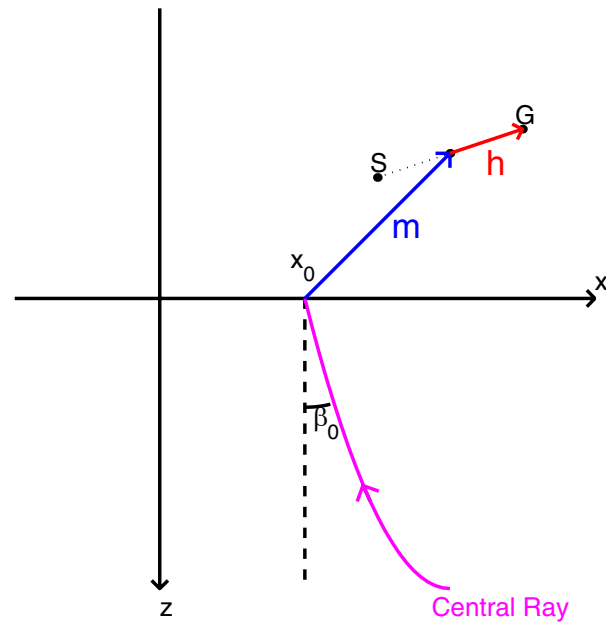

(b)

Figure 1 - Cartesian system of coordinates for: (a) Smooth topography; (b) Rugged topography.

$$
\begin{aligned}
T_{M F}(\mathbf{m}, \mathbf{h})=t_{0} & +\frac{1}{v_{0} K_{S}}\left[\sqrt{\left[K_{S}\left(m_{x}-h_{x}\right)+\sin \beta_{0}\right]^{2}+\left[K_{S}\left(m_{z}-h_{z}\right)+\cos \beta_{0}\right]^{2}}-1\right] \\
& +\frac{1}{v_{0} K_{G}}\left[\sqrt{\left[K_{G}\left(m_{x}+h_{x}\right)+\sin \beta_{0}\right]^{2}+\left[K_{G}\left(m_{z}+h_{z}\right)+\cos \beta_{0}\right]^{2}}-1\right],
\end{aligned}
$$

where

$$
\begin{gathered}
K_{S}=\frac{K_{N}-\sigma K_{N I P}}{1-\sigma}, \quad K_{G}=\frac{K_{N}+\sigma K_{N I P}}{1+\sigma}, \\
\sigma=\frac{h_{x}-h_{z} \tan \beta_{0}}{m_{x}-m_{z} \tan \beta_{0}+Q K_{N I P} \sin \beta_{0}},
\end{gathered}
$$

and

$$
Q=\left(m_{x}^{2}-h_{x}^{2}-m_{z}^{2}+h_{z}^{2}\right)+\left(m_{x} m_{z}-h_{x} h_{z}\right) \cos 2 \beta_{0} .
$$

\section{NUMERICAL EXPERIMENTS}

In order to check the accuracy of the traveltime formulas discussed in this work, we consider the simple $2 \mathrm{D}$ model depicted in Figure 2. It consists of two homogeneous acoustic layers, with velocities $1.75 \mathrm{~km} / \mathrm{s}$ and $2.5 \mathrm{~km} / \mathrm{s}$, respectively, separated by a curved interface. The measurement line has a rugged (nonsmooth) topography. We have used the ray tracing package SEIS88 (Červený \& Psěnsik, 1988) to model the reflection traveltimes for the reflecting interface. We have simulated a multiple coverage around the central point with $x_{0}=2 \mathrm{~km}$.

Figures $3-5$ show the modelled reflection traveltimes for three different configurations, Common-Source (CS), Common-Offset
(CO) and Common-Midpoint (CMP), and the respective approximation formulas, CRS smooth [CRS-S], equation (5), CRS rugged [CRS-R], equation (6), and Multifocus, equation (7). Also depicted are the relative errors for the three approximations.

As readily observed, the CRS-S formula gives poor approximations, whereas CRS-R and Multifocus present good results with relative errors of the same order.

We have also compared the exact reflection traveltimes with the corresponding diffraction traveltimes approximations, i.e., taking $K_{N I P}=K_{N}$ in CRS and Multifocus formulas. The objective of this experiment is to check the possibility of its use as a two-parameter search in the application of the CRS method. We note that such a strategy has been already implemented by 


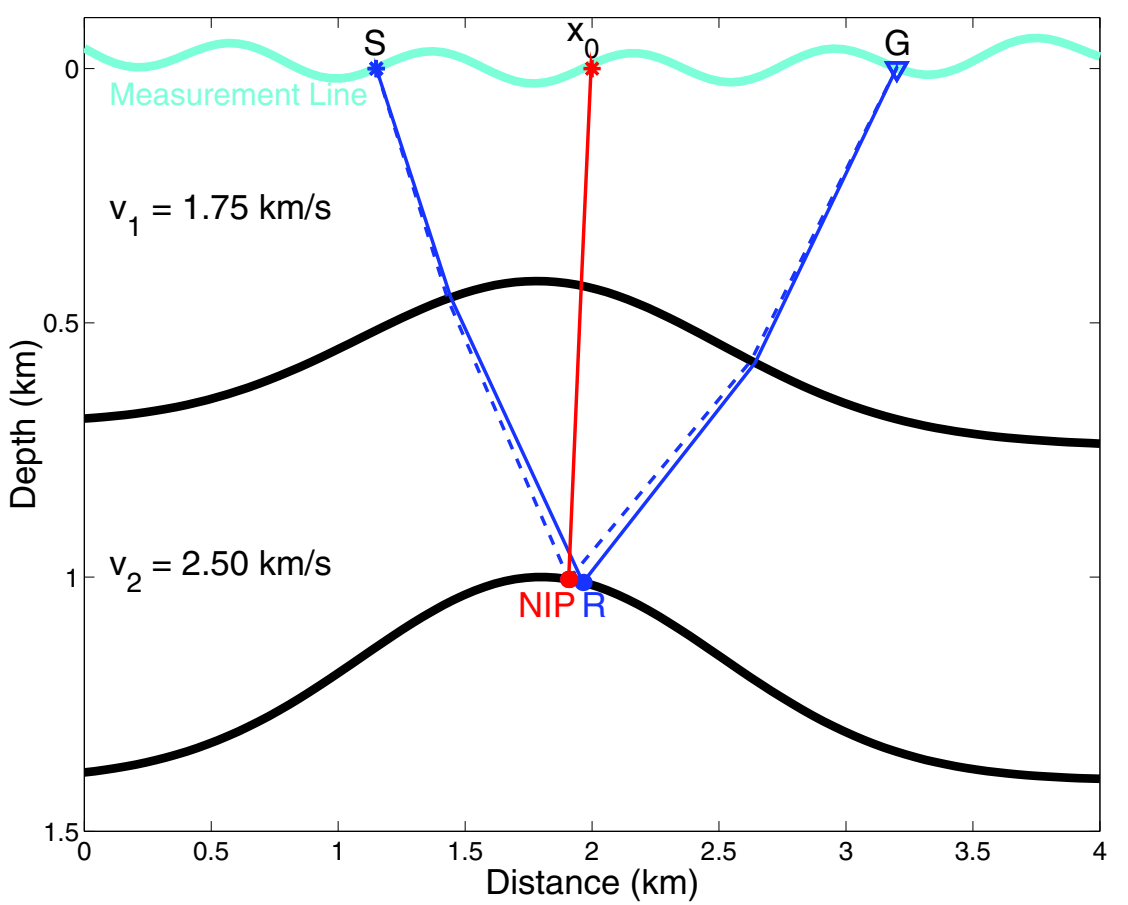

Figure 2-2D acoustic model for the numerical experiments. The Z0 ray is ploted in red, the reflection ray in blue and the diffraction ray in dashed blue. Also indicated are the normal-incidend-point (NIP) and the reflection point (R).
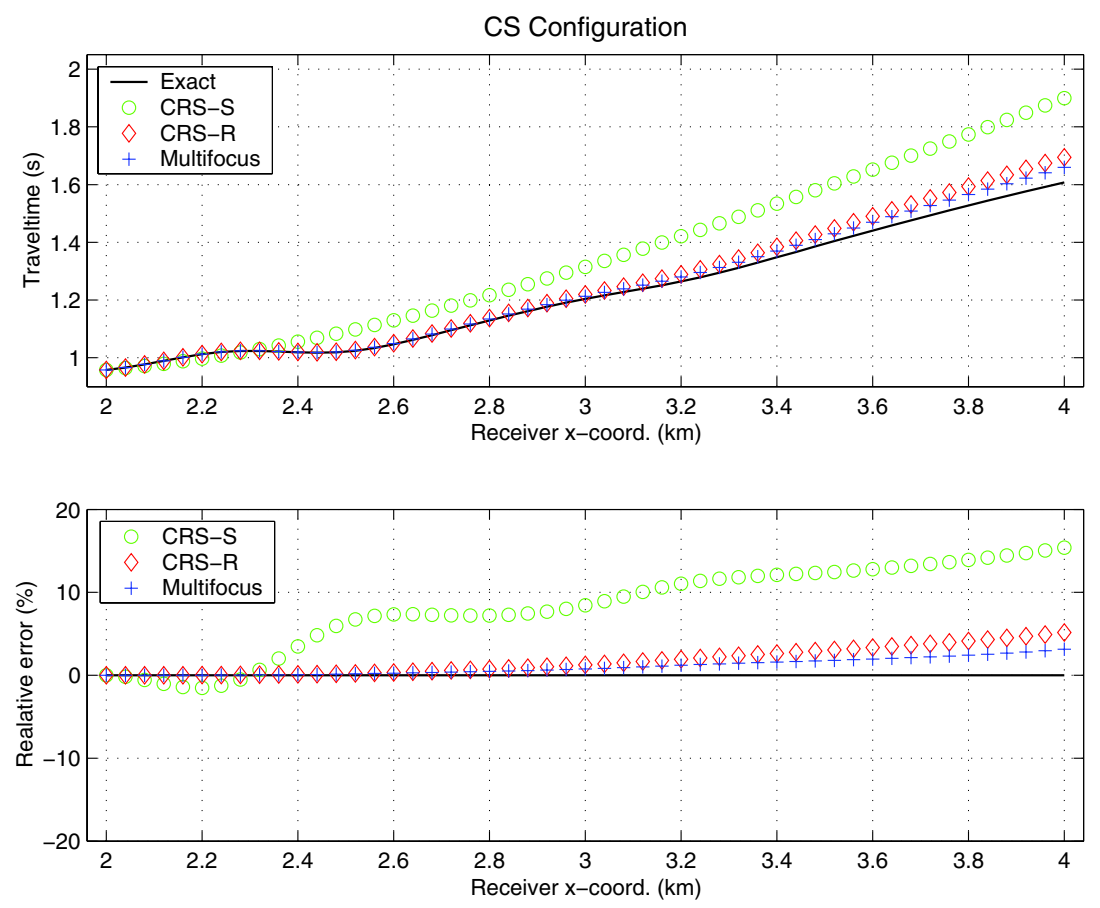

Figure 3 - Reflection traveltime approximations for a CS configuration with $x_{S}=2.0 \mathrm{~km}$. 

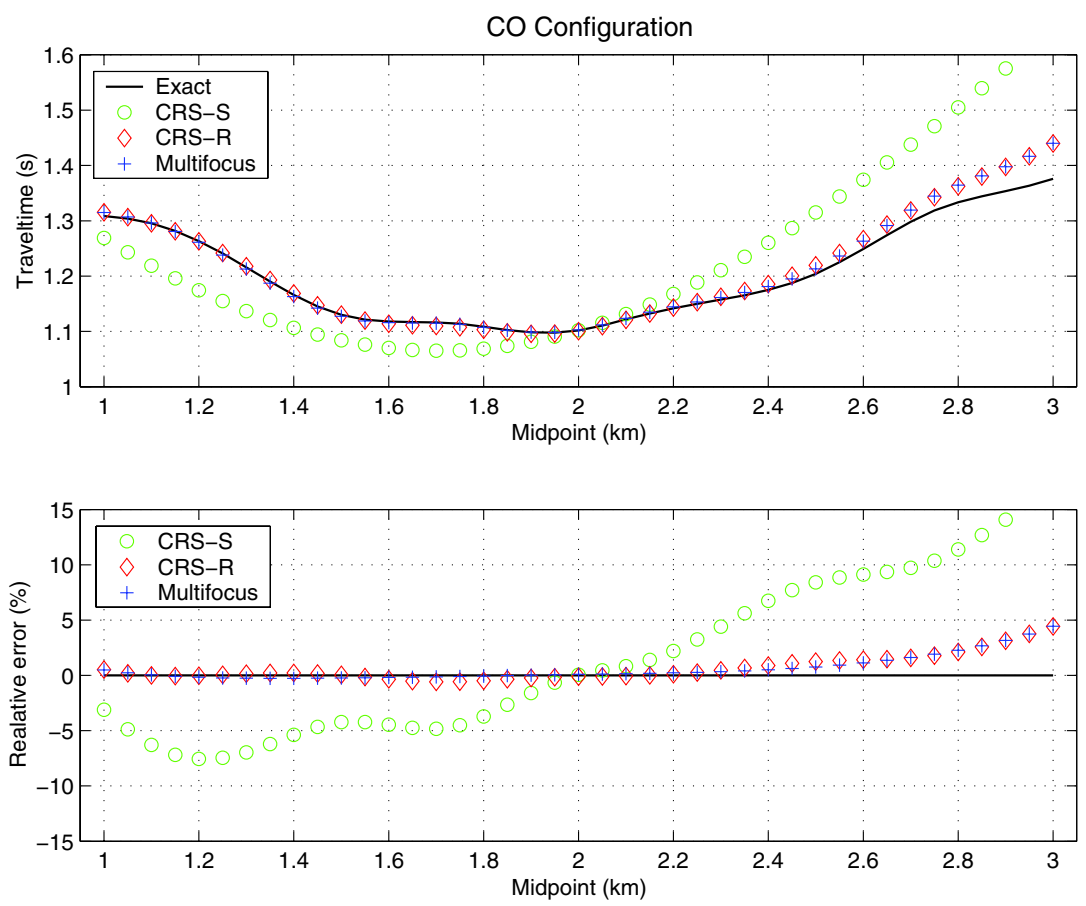

Figure 4 - Reflection traveltime approximations for a CO configuration with $h=0.5 \mathrm{~km}$.
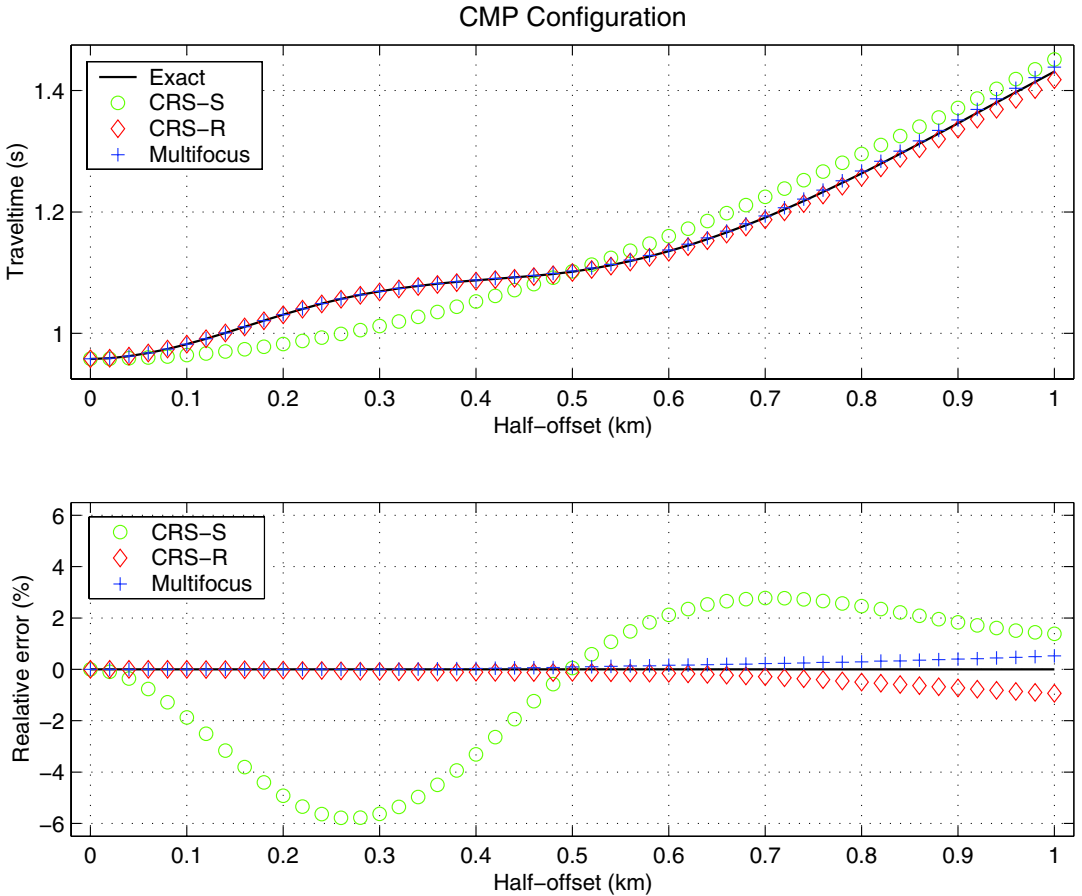

Figure 5 - Reflection traveltime approximations for a CMP configuration centered at $x_{m}=2.0 \mathrm{~km}$. 

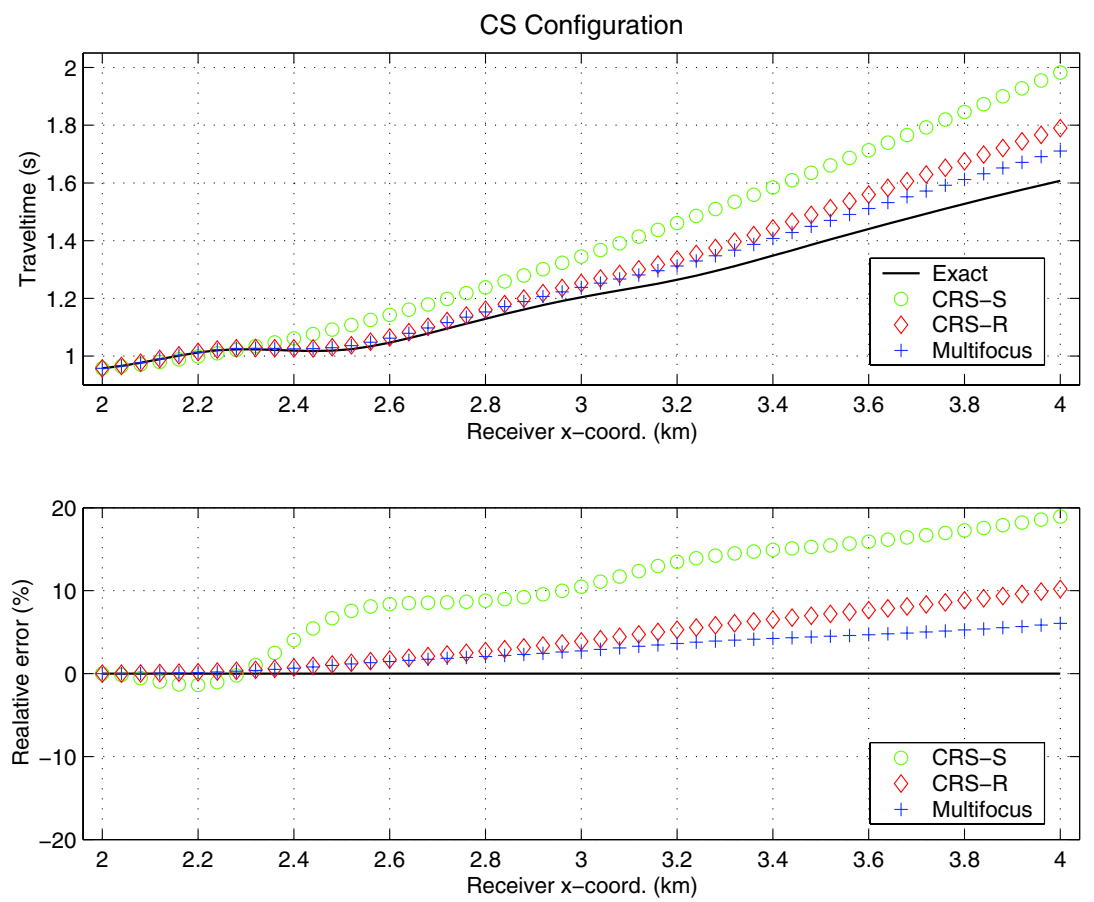

Figure 6 - Diffraction traveltime approximations for a CS configuration with $x_{S}=2.0 \mathrm{~km}$.
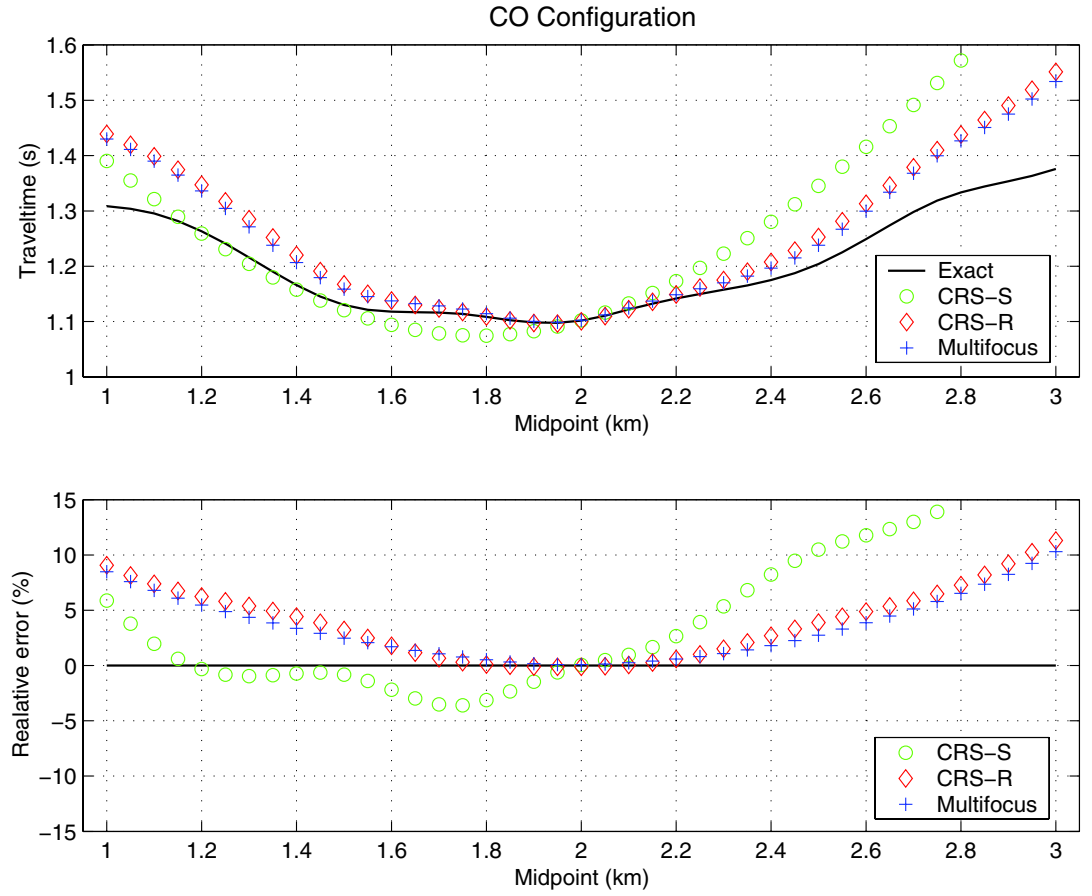

Figure 7 - Diffraction traveltime approximations for a C0 configuration with $h=0.5 \mathrm{~km}$. 
Garabito et al. (2003) in the case of Marmousi data with good results. Figures 6 and 7 depict the results obtained in the present experiment. Observe that the CMP configuration is not shown since the traveltime expressions are the same as in the previous case.

As expected, the relative errors were now increased. Once again, the CRS-S formula has the worst behaviour whereas CRS$R$ and Multifocus formulas behave similarly. We verify that, for small aperture the relative errors remain very reasunable, so that the CRS-R and Multifocus formulas for diffraction traveltimes are able to well approximate the exact (modelled) reflection traveltimes. As a conclusion, a two-parameter search in the CRS method using $K_{N I P}=K_{N}$ in the formulas, have the potential of producing good initial approximations for the CRS attributes.

\section{CONCLUSIONS}

We quickly revisited the Common-Reflection-Surface (CRS) and Multifocus traveltime moveouts in the case of a topographic measurement surface. By means of a simple synthetic example, we provided first comparisons on their accuracy and validity. Our results show that the approximation formulas for rugged topography yield good results, not only to approximate the exact (modelled) reflection traveltimes, but also as a two-parameter formula in the search for initial approximations for the CRS attributes.

\section{ACKNOWLEDGMENTS}

This work has been partially supported by the National Council of Scientific and Technological Research (CNPq), and Research Foundation of the State of São Paulo (FAPESP), Brazil. We also thank the sponsors of the Wave Inversion Technology (WIT) consortium

\section{REFERENCES}

ČERVENÝ V \& PSĚNSIK I. 1988. Ray tracing program package, Charles University, Czechoslovakia.

CHIRA P, TYGEL M, ZHANG Y \& HUBRAL P. 2001. Analytic CRS Stack formula for a $2 \mathrm{D}$ curved measurement surface and finite-offset reflections, Journal of Seismic Exploration, 5: 245-262.

CHIRA P. 2003. Empilhamento pelo método Superfície de Reflexão Comum 2-D com Topografia e Introdução ao caso 3-D, Federal University of Para, Brazil.

GARABITO G, CRUZ JCR, HUBRAL P \& TYGEL M. 2003. 2-D CommonReflection-Surface (CRS) stack based on simulated annealing and quasiNewton: Application to Marmousi data set, 7th WIT Report.

GELCHINSKY B, BERKOVITCH A \& KEYDAR S. 1999. Multifocusing homeomorphic imaging, Part I: Basic concepts and formulas, Journal of Applied Geophysics, 42: 229-242.

GUREVICH B, KEYDAR S \& LANDA E. 2002. Multifocusing imaging over an irregular topography, Geophysics, 67: 639-643.

HUBRAL P. 1983. Computing true amplitude reflections in a laterally inhomogeneous Earth, Geophysics, 48: 1051-1062.

HUBRAL P. 1999. Macro-model independent seismic reflection imaging, Journal of Applied Geophysics, 42: 137-148.

JÄGER R, MANN J, HÖCHT G \& HUBRAL P. 2001. Common-reflectionsurface stack: Image and attributes, Geophysics, 66: 97-109.

ZHANG Y, HÖCHT G \& HUBRAL P. 2002. Extended Abstracts, "Poster 166", 2D and 3D ZO CRS stack for a complex top-surface topography, 64th Annual Internat. Mtg., Eur. Assoc. Expl. Geophys.

\section{NOTES ABOUT THE AUTHORS}

German Garabito received his BSc (1986) in Geology from University Tomás Frias (UTF), Bolivia, his MSc in 1997 and PhD in 2001 both in Geophysics from the Federal University of Pará (UFPA), Brazil. Since 2002 he has been full professor at the geophysical department of UFPA. His research interests are data-driven seismic imaging methods such as the Common-Refection-Surface (CRS) method and velocity model inversion.

Pedro Chira-Oliva received his diploma in Geological Engineering (UNI-Peru/1996). He also received his MSc in 1997 and PhD in 2003, both in Geophysics, from Federal University of Pará (UFPA/Brazil). He took part of the project of scientific research i“3D Zero-Offset Common-Reflection-Surface (CRS) stacking" (2000-2002), sponsored by Oil Company ENI (AGIP Division - Italy) and the University of Karlsruhe (Germany). Since 2003 he is researcher of the UFPA, responsible for the scientific project "Generalization of the Common-Reflection-Surface (CRS) stacking applied to real data in the Amazon region", financed by the PROSET/CT-PETRO/CNPq. He is an associate member of the Society of Exploration Geophysicists (SEG), Brazilian Geophysical Society and also is member of the Wave Inversion Technology (WIT) Corsortium (Germany).

Martin Tygel received his B.Sc in physics from Rio de Janeiro State University in 1969, his MSc in Mathematics at the Catholic University of Rio de Janeiro 1976 and his PhD in 1979 from Stanford University, both in mathematics. He was a visiting professor at the Federal University of Bahia (PPPG/UFBa), Brazil, from 1981 to 1983 and at the Geophysical Institute of Karlsruhe University, Germany, in 1990. In 1984, he joined Campinas State University (UNICAMP) as an associate professor and since 
1992 as a full professor in Applied Mathematics. Professor Tygel has been an Alexander von Humboldt fellow from 1985 to 1987. In that period, he conducted research at the German Geological Survey (BGR) in Hannover. From 1995 to 1999, he was the president of the Brazilian Society of Applied Mathematics (SBMAC). In 2002, he received EAGE's Conrad Schlumberger Award and also UNICAMP's Zeferino Vaz Award for academic recognition in 1995 and 2004. Prof. Tygel is the founder in 2001 of the Laboratory of Geophysical Computing at UNICAMP. The Laboratory is a member of the Wave Inversion Technology (WIT) Consortium, with headquarters in Karlsruhe. Prof. Tygel's research interests are in seismic processing, imaging and inversion. Emphasis is aimed on methods and algorithms that have a sound wave-theoretical basis and also find significant practical application.

Lúcio T. Santos received his B.Sc. (1982) and M.Sc. (1985) in Applied Mathematics from the State University of Campinas (UNICAMP), Brazil. In 1991 he earned his PhD in Electrical Engineering also from UNICAMP. From 1985 to 1988 he was employed as a Teaching Assistant at the University of Sao Paulo (USP). Since 1988 he has been working for UNICAMP, first as an Assistant Professor and after 1999 as an Associate professor. From 1994 to 1995 he visited Rice University as a postdoc researcher and in 1998, 1999 and 2001 he was a visiting professor at the Geophysical Institute of Karlsruhe University (Germany). His professional interests include seismic modeling and imaging as well as nonlinear optimization. His present activities include the development of new approximations for the P-P reflection coefficient, alternative attributes for AVO analysis, and multiparametric traveltime formulas. He is a member of SBGf and SEG. 